\title{
Neonatal mortality at Leratong Hospital
}

\author{
J C Moundzika-Kibamba, ${ }^{1,2}$ MD, DCH, MSc (Med); F L Nakwa, ${ }^{2,3}$ MB BCh, MMed, FCPaed, Cert Neonatol \\ ${ }^{1}$ Department of Paediatrics and Child Health, Leratong Hospital, Johannesburg South Africa \\ ${ }^{2}$ Department of Paediatrics and Child Health, Faculty of Health Sciences, University of the Witwatersrand, Johannesburg, South Africa \\ ${ }^{3}$ Division of Neonatology, Chris Hani Baragwanath Academic Hospital, Johannesburg, South Africa
}

Corresponding author: J C Moundzika-Kibamba (jmoundzika@hotmail.com)

\begin{abstract}
Background. There has been a high demand for delivery services at Leratong Hospital; however, no study on the causes of neonatal mortality has been conducted. It was therefore essential to identify the causes of newborn deaths so as to implement policies that would advance neonatal care. Objectives. To determine the neonatal mortality rate (NMR), the primary causes of neonatal death and the occurrence of avoidable health factors. Methods. This prospective descriptive study was conducted at the neonatal unit of Leratong Hospital, Johannesburg, South Africa. Clinical records of all neonates who were admitted between April 2013 and July 2013 were reviewed.

Results. A total of 380 neonates were admitted to Leratong Hospital over the 4-month period and 46 newborns died. The mean age (standard deviation (SD)) of all neonates admitted was 5 (5.8) days. Their mean (SD) weight was 1824.5 (29) g. Almost $37 \%$ of neonates died within 24 hours of admission. The 3 most common causes of death were: prematurity (39\%), perinatal asphyxia (26\%) and infection (20\%). More than $60 \%$ of deaths occurred in the admission room. Three-quarters of neonates who died (74\%) were low-birth-weight neonates. Staff shortage was found to be a contributor in $63 \%$ of deaths. Thirty-seven per cent of neonates could not be ventilated due to a shortage of ICU beds. The significant predictors relating to neonatal death were: preterm birth (OR 3.1, 95\% CI 1.7 - 6.0), extremely low birth weight (OR 27.5; 95\% CI 8.2 - 92.6), very low birth weight (OR 5.0; 95\% CI 2.1 - 12.3) and birth by caesarean section (OR 3.2; 95\% CI 1.6 - 6.2).

Conclusion. The neonatal mortality rate at Leratong Hospital was lower than the rates found in other studies. Preterm birth, low birth weight and birth by caesarean section were the strongest predictors of death. These deaths could have been avoided through provision of high-care services and an adequate number of nurses who were trained in both newborn care and early detection of perinatal asphyxia.
\end{abstract}

S Afr J Child Health 2018;12(1):24-28. DOI:10.7196/SAJCH.2018.v12i1.1436

Each year there are an estimated 3.6 million neonatal deaths globally. ${ }^{[1]}$ These deaths occur mostly in low-income countries. However, neonatal mortality and morbidity is also a problem in high-income countries. ${ }^{[2]}$ Almost $41 \%$ of the 9.7 million deaths in children under the age of 5 occur in sub-Saharan Africa. ${ }^{[3]}$

South Africa has an unacceptably high infant mortality rate, with neonatal deaths accounting for $35-40 \%$ of all deaths of children younger than the age of 5 years. ${ }^{[4,5]}$ South Africa is also one of the countries which have not reached the Millennium Development Goal's 2015 deadline to reduce child mortality by two-thirds. ${ }^{[4]}$ Furthermore, deaths during the first 7 days of life account for $88 \%$ of South African neonatal deaths. ${ }^{[6]}$ Poor survival rates in neonates admitted to Chris Hani Baragwanath Academic Hospital, Johannesburg, were linked to premature birth in association with very low birth weight, but was also related to limited resources, especially the lack of mechanical ventilation. ${ }^{[7]}$

The present study was conducted at Leratong Hospital, a publicsector regional hospital in the West Rand region of Gauteng that renders secondary-level healthcare services. The institution is a site for the Perinatal Problem Identification Programme (PPIP), which is an audit tool for evaluating perinatal care that was designed and developed in South Africa. It is compulsory for all public health facilities to collect and report data to the National Department of Health using PPIP. In a meta-analysis of 7 before-after studies in lowand middle-income countries, perinatal mortality audit was shown to be associated with up to a $30 \%$ reduction in perinatal deaths. ${ }^{[8]}$

Neonatal care rendered at Leratong Hospital includes: basic newborn care of healthy infants; special care to infants with moderate risk of serious complications related to immaturity, illness, requiring nasal cannulae and antibiotics; Kangaroo Mother Care (KMC) provided to stable premature infants waiting for weight gain; high care (HC) and intensive care unit (ICU) which provide continuous positive airway pressure (CPAP) or mechanical ventilator support to infants with severe illness. A neonatal intensive care unit (NICU) is run by a paediatrician and it has four beds and two ventilators. The unit lacked sufficient NICU equipment.

The aims of the present study were to describe the causes of neonatal deaths and to identify health services factors associated with neonatal deaths at Leratong Hospital between 15 April 2013 and 15 July 2013.

\section{Methods}

This was a prospective review of the clinical records of all neonates admitted to the hospital during the study period (15 April 2013 - 15 July 2013). Variables were age, birth weight, gender, race, place of origin, reason for admission and cause of death. The primary causes of neonatal death were categorised using the Perinatal Problem Identification Programme (PPIP). Health factors examined were: access to high-care services, access to the NICU and the number of staff on duty, admission room care for all neonates from the Leratong labour ward and theatre as well as those transferred in from other hospitals. Inborn mortality rate was calculated from the deaths and births at Leratong only and did not include the other hospitals. Questionnaires were used to collect information, and consent to use clinical records was obtained from the mothers of the neonates. Descriptive statistics were used to describe the frequencies and percentages of variables. Logistic regression of variables was applied to predict mortality.

\section{Sampling}

All neonates who died at Leratong Hospital during the study period and neonates born before arrival and outside Leratong Hospital were included in the study. However, neonates whose mothers did not give consent and patients whose records could not be traced were excluded.

\section{Data collection and statistical analysis}

All the information was captured on a data capture sheet with details 
of the mother, neonate and staffing. For each cause of death, the health services factors examined were: the presence or absence and availability of CPAP, ventilators; as well as the number and experience of doctors and nurses on duty.

Data were entered into an MS Excel spreadsheet and statistical analysis was done using the Epi Info software programme (Centers for Disease Control and Prevention, USA). Continuous variables were expressed as the mean (standard deviation (SD)) while categorical variables were summarised using frequencies and percentages. Logistic regression was conducted on a univariate level to identify the predictors of neonatal death. Variables with significant levels $(p=0.05)$ of prediction of death were then entered into a multiple logistic regression analysis. Results were expressed as odds ratios (OR) with corresponding $p$-values and $95 \%$ confidence intervals (CIs).

\section{Ethics}

The study was approved by the Human Research Ethics Committee (Medical) of the University of the Witwatersrand (ref. no. M120867), the Gauteng Department of Health (Director, West Rand District Council), and the hospital management.

\section{Results}

\section{Characteristics of admitted neonates}

There were $380 \mathrm{admissions} \mathrm{to} \mathrm{the} \mathrm{neonatal} \mathrm{unit} \mathrm{of} \mathrm{which} 256$ (67\%) were inborn patients. A third of the total admissions came from home (29\%) or from another facility (4\%). There were 196 (51.6\%) term neonates. Eighty percent of all neonates were delivered by normal vaginal delivery. Fifty percent of the patients were lowbirth-weight neonates. Approximately half of the neonates were admitted to the unit for less than 7 days (Table 1).

\section{Neonatal mortality}

A total of 46 neonates died (12.1\% of total admissions); $41.3 \%$ died within 24 hours of admission. Their mean (SD) age was 5 (5.8) days.

Of the total deaths, $28 \%$ of patients were between $1500 \mathrm{~g}-2499 \mathrm{~g}$, followed by $26 \%$ in the $2500 \mathrm{~g}$ weight category, and $22 \%$ were in the category of neonates weighing $<999 \mathrm{~g}$. The mean (SD) weight of those who died was 1824.5 (29) g. Seventy-four percent of deaths were early neonatal deaths, with the higher proportion occurring in the group of neonates with weight $>1500 \mathrm{~g}$. Their mean stay in hospital was 5 (19) days. Sixty-three percent died in the admission room, followed by the NICU (15.2\%) and the labour ward (10.9\%).

\section{Mortality rates}

The inborn neonatal mortality rate was $17.8 / 1000$ live births, with the early neonatal mortality rate (ENMR) at 14.8/1 000 live births, and the late neonatal mortality rate (LNMR) was 3.0/1 000 live births. The inpatient mortality rate was $12.1 \%$.

\section{Causes of deaths}

Prematurity-related (39\%), perinatal asphyxia (26\%), infection (20\%), congenital abnormalities (9\%) and other (6\%) were the most common causes of death.

\section{Health services factors associated with death}

In two-thirds of deaths (63\%) the nurse-to-neonate ratio was more than 1:10. Additionally, during day and night shifts there was an average of one neonatal-trained professional nurse in the admission room. The most common identifiable administrative factor related to death was the lack of NICU beds with ventilators (37\%) in the category of neonates $>1000 \mathrm{~g}$.

\begin{tabular}{|c|c|c|c|}
\hline Description & Admissions $(N=380), n(\%)$ & Deaths $(N=46), n(\%)$ & Deaths per category (\%) \\
\hline \multicolumn{4}{|l|}{ Place of origin } \\
\hline Leratong (inborn) & $256(67.4)$ & $35(76.1)$ & 13.7 \\
\hline Home & $110(28.9)$ & $5(10.9)$ & 4.5 \\
\hline Dr Yusuf Dadoo & $8(2.1)$ & $3(6.5)$ & 37.5 \\
\hline Carletonville & $3(0.8)$ & $2(4.3$ & 66.7 \\
\hline Private & $2(0.5)$ & 0 & 0 \\
\hline CH Baragwanath & $1(0.3)$ & $1(2.2)$ & 100 \\
\hline \multicolumn{4}{|l|}{ Gender } \\
\hline Male & $202(53.2)$ & $22(47.8)$ & 10.9 \\
\hline Female & $178(46.8)$ & $24(52.2)$ & 13.5 \\
\hline \multicolumn{4}{|l|}{ Gestational age } \\
\hline Term & $196(51.6)$ & $13(28.3)$ & 6.6 \\
\hline Preterm & $184(48.4)$ & $33(71.7)$ & 17.9 \\
\hline$<28$ weeks & $15(8.1)$ & $10(30.3)$ & 66.7 \\
\hline 28 - 32 weeks & $41(22.3)$ & $11(33.3)$ & 26.8 \\
\hline 32 - 36 weeks & $128(69.6)$ & $12(36.4)$ & 9.4 \\
\hline \multicolumn{4}{|l|}{ Mode of delivery } \\
\hline Normal vaginal & $306(80.5)$ & $27(58.7)$ & 8.8 \\
\hline Caesarean section & $74(19.5)$ & $19(41.3)$ & 25.7 \\
\hline \multicolumn{4}{|l|}{ Birth weight (grams) } \\
\hline $500-999$ & $15(4)$ & $10(21.7)$ & 66.7 \\
\hline $1000-1499$ & $41(10.8)$ & $11(23.9)$ & 26.8 \\
\hline $1500-2499$ & $132(34.7)$ & $13(28.3)$ & 9.8 \\
\hline$>2500$ & $192(50.5)$ & $12(26.1)$ & 6.2 \\
\hline \multicolumn{4}{|c|}{ Duration of stay (days) } \\
\hline$<1$ & $37(9.7)$ & $19(41.3)$ & 51.3 \\
\hline $1-3$ & $71(18.7)$ & $8(17.4)$ & 11.3 \\
\hline $4-7$ & $101(26.6)$ & $11(23.9)$ & 10.9 \\
\hline $8-28$ & $171(45)$ & $8(17.4)$ & 4.7 \\
\hline
\end{tabular}




\section{Logistic regression analysis of predictors of mortality}

Preterm delivery (OR 3.1; 95\% CI 1.7 - 6.0), extremely low birthweight (OR 27.5; 95\% CI 8.2 - 92.6), very low birth-weight (OR 5.0; 95\% CI 2.1 - 12.3), and caesarean section (OR 3.2; 95\% CI 1.6 - 6.2) were the four factors associated with neonatal death in the univariate analysis. In the multivariate model, the most important predictors of mortality were birth weight (OR 27.3; 95\% CI 7.9 - 94.3) and caesarean section (OR 3.3; 95\% CI 1.6 - 6.8) (Table 3).

\section{Discussion}

This prospective study provided the causes and health factors relating to neonatal deaths. The overall in-hospital neonatal mortality rate at Leratong Hospital was lower than the rates found in other studies in sub-Saharan Africa. ${ }^{[9,10]}$ However, the study was only over a 3-month period and it did not include deliveries and deaths from surrounding areas. The neonatal mortality rate (NMR) for the year 2013 (13.7/1 000 live births) was lower than the rate in South Africa (15/1 000 live births). ${ }^{[1]}$ The NMR was similar to the NMR at Central and Eastern Tshwane district (13.6/1 000 live births) in $2011,{ }^{[12]}$ but it was higher than the rate in the West Rand region (8/1 000 live births).

There was a slight majority of male neonates in admissions and female in deaths, as opposed to male predominance for both admissions (58\%) and deaths (63\%) at Empangeni Hospital in KwaZulu-Natal. ${ }^{[13]}$ There was no explanation for our finding. Hoque et al. ${ }^{[13]}$ reported a male predominance and noted the issue of vulnerability of male neonates as it is found universally in other studies. In addition, low-birth-weight neonates $(<2500$ g) accounted for higher rates of admissions and deaths in both studies. Our results revealed that the most common causes of neonatal mortality were related to prematurity, perinatal asphyxia, infection and congenital abnormalities, and were in keeping with the literature. ${ }^{[13,14]}$ Prematurity and asphyxia represent more than 65\% of all admissions and deaths, as reported in the seventh and ninth Saving Babies' Reports. ${ }^{[14,15]}$ Most neonates died within their first week of life (17.3/1 000 live births), and in 37\% of cases death occurred within 24 hours of admission. The deaths were the result of multiple factors, including the following: severity of the disease (prematurity and extremely low birth-weight); insufficient number of trained nurses on duty; inadequate equipment to monitor the sick neonate; as well as limited access to ICU beds and ventilators. Deaths occurring in the first 24 hours of admission to a hospital may reflect a range of quality-of-care issues such as late presentation and/ or inadequate first-line assessment and management on admission to hospital. ${ }^{[14]}$ Zupan et al. ${ }^{[16]}$ stated that globally, three-quarters of neonatal deaths happen in the first week after birth.

Table 2. Details of the causes of deaths $(N=46)$

\begin{tabular}{ll}
\hline Description & Deaths, $\boldsymbol{n}(\%)$ \\
\hline Prematurity-related & $18(39.1)$ \\
Extreme multi-organ immaturity & $9(50)$ \\
Respiratory distress syndrome & $6(33.3)$ \\
Pulmonary haemorrhage & $2(11.1)$ \\
Intraventricular haemorrhage (grade III/IV) & $1(5.6)$ \\
Perinatal asphyxia & $12(26.1)$ \\
Hypoxic ischaemic encephalopathy (stage II/III) & $10(83.3)$ \\
Persistent pulmonary hypertension of the newborn (PPHN) & $2(16.7)$ \\
Infection & $9(19.6)$ \\
Sepsis (2 contaminants with coagulase-negative Staphylococcus - laboratory or clinical suspicion) & $7(77.8)$ \\
& $1(11.1)$ \\
Nosocomial infection (Klebsiella pneumoniae) & $1(11.1)$ \\
Meningitis (Escherichia coli) & $4(8.7)$ \\
Congenital abnormalities & $3(75)$ \\
Gross congenital abnormalities & $1(25)$ \\
Down syndrome & $3(6.5)$ \\
Other & $1(33.3)$ \\
Aspiration pneumonia & $2(66.7)$ \\
Other &
\end{tabular}

Table 3. Logistic regression analysis of predictors of mortality

\begin{tabular}{|c|c|c|c|c|c|c|}
\hline \multirow[b]{2}{*}{ Variable } & \multicolumn{3}{|c|}{ Univariate } & \multicolumn{3}{|c|}{ Multivariate } \\
\hline & Unadjusted OR & $95 \% \mathrm{CI}$ & $p$-value & Adjusted OR & $95 \% \mathrm{CI}$ & $p$-value \\
\hline \multicolumn{7}{|l|}{ Gestational age } \\
\hline Term & 1 & & & & & \\
\hline Preterm & 3.1 & $1.7-6.0$ & 0.001 & 3.2 & $1.6-6.1$ & 0.000 \\
\hline \multicolumn{7}{|l|}{ Delivery } \\
\hline Normal vaginal & 1 & & & & & \\
\hline Caesarean & 3.2 & $1.6-6.2$ & 0.001 & 3.3 & $1.6-6.8$ & 0.000 \\
\hline \multicolumn{7}{|l|}{ Birth weight (g) } \\
\hline $500-999$ & 27.5 & $8.2-92.6$ & 0.000 & 27.3 & $7.9-94.3$ & 0.000 \\
\hline $1000-1499$ & 5.0 & $2.1-12.3$ & 0.000 & 4.6 & $1.9-11.5$ & 0.001 \\
\hline $1500-2499$ & 1.4 & $0.6-3.1$ & 0.443 & 1.2 & $0.5-2.7$ & 0.709 \\
\hline$>2500$ & 1 & & & & & \\
\hline
\end{tabular}


Preterm birth and low birth-weight had a high mortality rate in this analysis. In Hoque's report, ${ }^{[13]}$ preterm birth resulted in higher rates of admission (44\%) and death (68\%), and almost half of all deaths occurred among the very low birth weight patients $(<1500 \mathrm{~g})$. Katz et al. ${ }^{[17]}$ used a pooled analysis of 20 cohorts from Asia, Africa and Latin America and found that neonatal mortality and relative risks increased with decreasing gestational age across studies and regions. Low birth-weight neonates represented nearly $74 \%$ of our deaths, identical to what was seen in many developing countries with limited resources, where they account for $60-80 \%$ of neonatal deaths. ${ }^{[18]}$

On univariate logistic regression analysis, gestational age and birth-weight were the significant predictors of death. Preterm birth was associated with increased mortality risk compared with term birth. Similar results were documented in a rural hospital in KwaZulu-Natal, ${ }^{[13]}$ and in both reports at Charlotte Maxeke Johannesburg Academic Hospital, ${ }^{[1,20]}$ where the main determinants of survival were birth-weight and gestational age. Neonates with a birth-weight $<1000 \mathrm{~g}$ exhibited higher mortality (66.7\%) in the first week of life. The survival rate was poorer (near zero) than that reported at Chris Hani Baragwanath Academic Hospital (34\%) ${ }^{[7]}$ and at Charlotte Maxeke Johannesburg Academic (34.9\%), ${ }^{[19]}$ which are both tertiary hospitals in Johannesburg. However, the survival rate was comparable to the $5 \%$ recorded in KwaZulu-Natal. ${ }^{[13]}$ Due to limited resources in our hospital, extremely-low-birth-weight neonates were given insufficient high care support, hence they did not qualify for ICU, neither were they given surfactant nor put on nasal continuous positive airway pressure (NCPAP). The cut-off birth-weight used was $1000 \mathrm{~g}$ for these life-sustaining measures. Perinatal asphyxia was the second most prominent cause of neonatal admissions and mortality at $26.8 \%$ and $26 \%$, respectively. In $58 \%$, labour-related asphyxia was the cause of death in $>2500$ g neonates. There were challenges associated with monitoring fetal distress as the partogram was not utilised correctly and there was a shortage of cardiotocogram machines. Equipment to detect fetal distress was not readily available, and if detected the time to deliver the newborns might have been insufficient due to a staff shortage (midwife to prepare the patient, porter and anaesthetist). Out of 16 caesarean sections performed on neonates who weighed $>1000 \mathrm{~g}$, 12 neonates $(75 \%)$ had a low Apgar score $(<5 / 10)$ at 1 minute. On the multivariate model, the study found that caesarean section was an important predictor of death. Surprisingly, the finding was contrary to other data, ${ }^{[19,20]}$ which reported that delivery by caesarean section improved the chance of survival compared with neonates born by normal vaginal delivery. A possible reason for the differences was the lack of information on the decision-to-delivery interval (DDI) for emergency caesarean sections at Leratong Hospital, and was not analysed in this study. Neonatal infection, although the fourth cause of admission (10\%), represented the third cause of death $(20 \%)$ at Leratong Hospital. This was comparable to the mortality rate due to sepsis $(20.8 \%)$ in the Johannesburg Hospital neonatal unit in 2003. ${ }^{[21]}$ Among the deaths related to infection, sepsis accounted for almost $78 \%$ of deaths. Bryce et al. ${ }^{[22]}$ and Rhoda ${ }^{[23]}$ noted that preventing neonatal infection is complex, especially where access to health facilities is limited. In our neonatal ward, neonates shared the same overhead heated bed (radiant warmer) or neonates with sepsis were not cohorted. Thus, there was no space for isolation. Inadequate hand hygiene was an important factor that contributed to sepsis. The adherence to infection prevention control measures was not consistent.

The high neonatal mortality observed in our results was also related to some local factors in the health system and were seen in other reports. ${ }^{[24-26]}$ The study identified an insufficient number of personnel and inadequate neonatal facilities as the main administrative problems associated with deaths (37\%). More deaths (63\%) occurred in the admission room than in the NICU (15\%). The skilled and trained nurse-to-neonate ratio in the admission room was $\geq 1: 10$. The work load, coupled with shortage of trained nurses during the day and night shifts, was a major challenge to newborn survival. However, the logistic regression analysis did not find the lack of supervision of medical doctors to be a predictor of death. In order to reduce neonatal deaths, Velaphi and Rhoda ${ }^{[25]}$ recommended that the emphasis must be placed on providing adequate nursing and medical staff in our labour, delivery and neonatal wards, with appropriate training and equipment.

\section{Study strengths and limitations}

As the data employed in our study were prospective, it was possible to assess data accurately. The study identified problems in the management of sick newborns in our unit and provided evidence to facilitate change. The limitations of this study were: $(i)$ the short period of data collection for analysis; (ii) the small sample size; and (iii) the study did not include deliveries and deaths from surrounding areas.

\section{Conclusion}

The study found the neonatal mortality rate at Leratong Hospital to be lower than rates recorded elsewhere in South Africa. Our results revealed that the most common causes of neonatal admissions and mortality were similar to those in other hospitals. Most neonates died within the first week of life as reported in the literature. Preterm delivery, low birth-weight and caesarean section were major predictors of death. A high number of neonatal deaths were avoidable by providing high-care services (including NCPAP and surfactant), as well as an adequate number of nurses trained in newborn care in the admission room. These factors improve access to the neonatal ICU, aid the early detection of perinatal asphyxia and improve neonatal resuscitation rates.

Acknowledgements. We wish to acknowledge and thank Prof. Peter Cooper for reviewing the questionnaire and Mr Cornelius Nattey for initial assistance with the statistical analysis.

Author contributions. Writing of the questionnaire, data collection and manuscript preparation were done by JCMK and FLN was involved in drafting the manuscript. Both authors contributed to the final manuscript. Funding. None.

Conflicts of interest. None.

1. Lawn JE, Kerber K, Enweronu-Laryea C, Cousens S. 3.6 million neonatal deaths - what is progressing and what is not? Semin Perinatol 2010;34:371-386. https://doi.org/10.1053/j.semperi.2010.09.011

2. Lawn JE, Osrin D, Adler A, Cousens S. Four million neonatal deaths: Counting and attribution of cause of death. Paediatr Perinat Epidemiol 2008;22:410-416. https://doi.org/10.1111/j.1365-3016.2008.00960.x

3. Rutherford ME, Mulholland K, Hill PC. How access to health care relates to under-five mortality in sub-Saharan Africa: Systematic review. Trop Med Int Health 2010;15:508-519. https://doi.org/10. 1111/j.1365-3156.2010.02497.x

4. Baleta A. World report. South Africa takes steps to reduce perinatal mortality. Lancet 2011;377:1303-1304. http://doi.org/10.1016/S0140-6736(11)60523-0

5. Child mortality in South Africa: Minister of Health Briefing, 2013: https://pmg. org.za/committee-meeting/15489 (accessed 14 September 2017).

6. Saloojee H, Velaphi SC. Neonatal disorders. In: Kibel M, Haroon S, Westwood T eds. Child Health for All. Cape Town: Oxford University Press, 2008:317-328.

7. Velaphi SC, Mokhachane M, Mphahlele RM, Beckh-Arnold E, Kuwanda ML, Cooper PA. Survival of very-low-birth-weight infants according to birth weight and gestational age in a public hospital. S Afr Med J 2005;95:504-509.

8. Pattinson R, Kerber K, Waiswa P, et al. Perinatal mortality audit: Counting, accountability, and overcoming challenges in scaling up in low- and middleincome countries. Int J Gynaecol Obstet 2009;107:S113-S121. https://doi. org/10.1016/j.ijgo.2009.07.011

9. Kinney MV, Kerber KJ, Black RE, et al. Sub-Saharan Africa's mothers, newborns, and children: Where and why do they die? PLoS Med 2010;7(6):e1000294. https://doi.org/10.1371/journal.pmed.1000294

10. Greenfield D, Rhoda N, Pattinson RC. Ten years of the National Perinatal Care Surveys. In: Saving Babies 2008 - 2009: Seventh Report on Perinatal Care in South Africa. Pattinson RC, ed. Pretoria: Tshepesa Press, 2011:46. 
11. You D, Hug l, Ejdemyr S, Beise J. Level \& Trends in Child Mortality. Report 2015. Estimates Developed by the UN Inter-agency Group for Child Mortality Estimation. United Nation's Children's Fund, New York, 2015.

12. Lloyd LG, de Witt TW. Neonatal mortality in South Africa: How are we doing and can we do better? S Afr Med J 2013;103:518-519. https://doi.org/10.7196/ SAMJ.7200

13. Hoque M, Haaq S, Islam R. Causes of neonatal admissions and deaths at a rural hospital in KwaZulu-Natal, South Africa. S Afr J Epidemiol Infect 2011;26:2629.

14. Pattinson RC. Saving Babies 2008 - 2009: Seventh report on perinatal care in South Africa. Pretoria: Tshepesa Press, 2011.

15. Pattinson RC, Rhoda NR. Saving Babies 2012 - 2013: Ninth report on perinatal care in South Africa. Pretoria: Tshepesa Press, 2014.

16. Zupan J, Aahman E. Perinatal Mortality for the year 2000: Estimates Developed by WHO. Geneva: World Health Organization, 2005.

17. Katz J, Lee ACC, Kozuki N, Lawn JE, Cousens S, Blencowe H, et al. Mortality risk in preterm and small-for-gestational-age infants in low-income and middle-income countries: A pooled country analysis. Lancet 2013;382:417-425. https://doi.org/doi.org/10.1016/S0140-6736(13)60993-9

18. Lawn JE, Cousens S, Zupan J. 4 million neonatal deaths: When? Where? Why? Lancet 2005;365:891-900. https://doi.org/doi.org/10.1016/S01406736(05)71048-5

19. Ballot DE, Chirwa TF, Cooper PA. Determinants of survival in very low birth weight neonates in a public sector hospital in Johannesburg. BMC Pediatrics 2010,10:30. https://doi.org/doi.org/10.1186/1471-2431-10-30
20. Kalimba EM, Ballot DE. Survival of extremely low-birth-weight infants. S Afr J Child Health 2013;7:13-16. https://doi.org/doi.org/10.7196/SAJCH.488

21. Motara F, Ballot DE, Perovic O. Epidemiology of neonatal sepsis at Johannesburg Hospital. S Afr J Epidemiol Infect 2005;20:90-93. https://doi.org/10.1080/1015 8782.2005.11441243

22. Bryce J, Black RE, Victoria CG. Millennium Development Goals 4 and 5: Progress and challenges. BMC Medicine 2013;11:225. https://doi.org/doi. org/10.1186/1741-7015-11-225

23. Rhoda NR. National newborn care: Key findings and recommendations. The 5th South African Child Health Priorities Conference. Bloemfontein, 3 - 5 December 2014.

24. Wall SN, Lee ACC, Carlo W, et al. Reducing intrapartum-related neonatal deaths in low- and middle-income countries - what works? Semin Perinatol 2010;34:395-407. https://doi.org/doi.org/10.1053/j.semperi.2010.09.009

25. Velaphi S, Rhoda N. Reducing neonatal deaths in South Africa - are we there yet, and what can be done? S Afr J Child Health 2012;6:67-71. https://doi. org/10.7196/SAJCH.493

26. Friberg IK, Kinney MV, Lawn JE, et al. Sub-Saharan Africa's mothers, newborns, and children: How many lives could be saved with targeted health interventions? PLoS Med 2010;7(6):e1000295. https://doi.org/10.1371/journal. pmed.1000295

Accepted 21 September 2017. 